\title{
Young African universities take the lead
}

\author{
Having long played the role of collaborators with other, more renowned, institutions, historically disadvantaged \\ South African universities are now challenging the status quo - and emerging as leaders.
}

\section{José Nicolás Orce and Sifiso Ntshangase}

C uring a celebration of the International Day of Light, members of the University of the Western Cape (UWC) implored school-age children living at a local shelter to aspire to study at the university. In response, one little boy stood up and said, "I am very disappointed with UWC. I will go to UCT!”, before sitting down again without another word. UCT is the University of Cape Town, a historically privileged university that outperforms other institutions on the African continent according to The Times World University Rankings (https://go.nature.com/3igd43s). By contrast, UWC is among the so-called disadvantaged institutions in South Africa. The prejudice expressed by the little boy is unfortunately common, but momentum is building to turn this around.

UWC and the University of Zululand (UZ) were both established in 1960, when university education was segregated. The intellectual capabilities of African, Coloured and Indian South Africans - together regarded as the Black community - were deemed inferior, and thus incapable of the rigour and demands of science. These Universities offered ill-equipped facilities for postgraduate studies, so the path to higher education and excellence in research was an arduous one. Changing this history is no simple task, but our recent success story in nuclear physics offers a blueprint for future endeavours.

\section{Bringing about change}

As is the case with any long-term goals, efforts to achieve them are built upon the shoulders of many, including pioneers who open the doors for others to follow. This was certainly true for us, when our nuclear physics group proposed a leading experiment to be conducted at CERN ${ }^{1}$. We received support from the South AfricaCERN collaboration, which, at that time, was led by Krish Bharuth-Ram (Durban University of Technology, DUT) and the late Jean Cleymans (UCT). The main aim of this collaboration is to make the facilities at CERN available to South African researchers, engineers, technicians and students.

Our research proposal was finally accepted in 2013, resulting - together

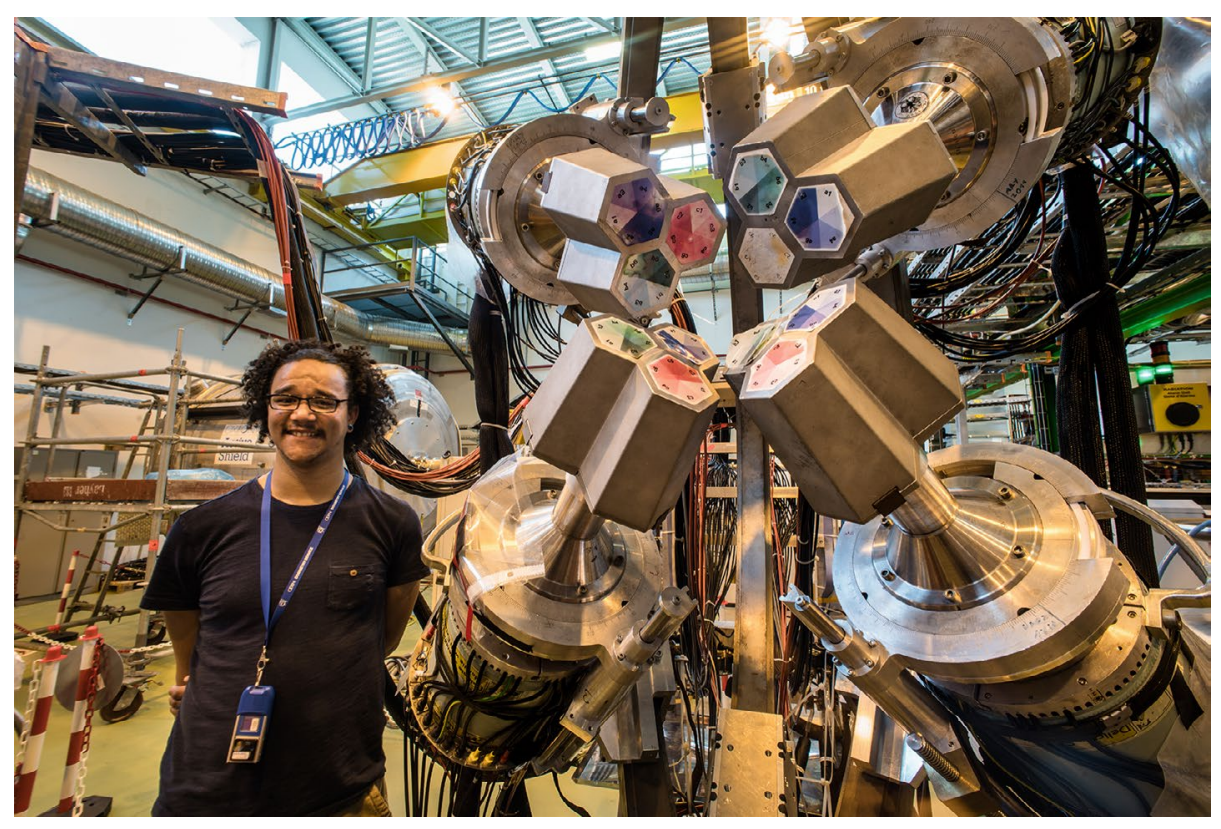

Fig. 1 | Kenzo Abrahams in front of the Miniball germanium array at CERN. Miniball is an array of 24 high-purity germanium crystals that was designed for low-multiplicity experiments with low-intensity radioactive ion beams at CERN's ISOLDE. Kenzo Abrahams from UWC conducted his PhD experiments and supported experimental campaigns using Miniball. Credit: Courtesy of CERN.

with Bharuth-Ram's leadership — in a Memorandum of Understanding between the National Research Foundation of South Africa and the Isotope mass Separator On-Line facility (ISOLDE) at CERN. This memorandum, signed in October 2015, formalizes the South African membership to the ISOLDE Collaboration and allows any South African scientist to lead experiments at the facility. Since then, several research proposals led by other South African institutions have been submitted and approved.

Among them was a proposal for an experiment conducted in July 2017, which was the first official experiment led by an African institution at CERN and joined ISOLDE and Bharuth-Ram's research team in material science at DUT, which had been active in ISOLDE since 1993. Our team comprised 13 researchers and students from UWC and UZ together with collaborators from CERN, the University of York and other European institutions. CERN auspiciously called the experiment 'Ubuntu', which means 'humanity' in the indigenous language of Xhosa, one of the official languages of South Africa (https://go.nature. com/3CMRoDM).

The analysis of the Ubuntu experiment's data was led by UWC's former postgraduate student Kenzo Abrahams, who completed his PhD in April 2021 (Fig. 1). Besides uncovering that protons and neutrons act more collectively than expected for the atomic nucleus to attain an oblate shape, his work also proves to the world that South African students can run, lead and complete the highest demanding scientific tasks at world-leading physics laboratories. This is only one of many examples of the work our students and postdocs have already published in high-impact journals ${ }^{2-9}$, and who have moved on to work in world-class laboratories in Japan (RCNP), China (Lanzhou), France (Lyon) or Canada (TRIUMF). These South African researchers have developed new ideas with 


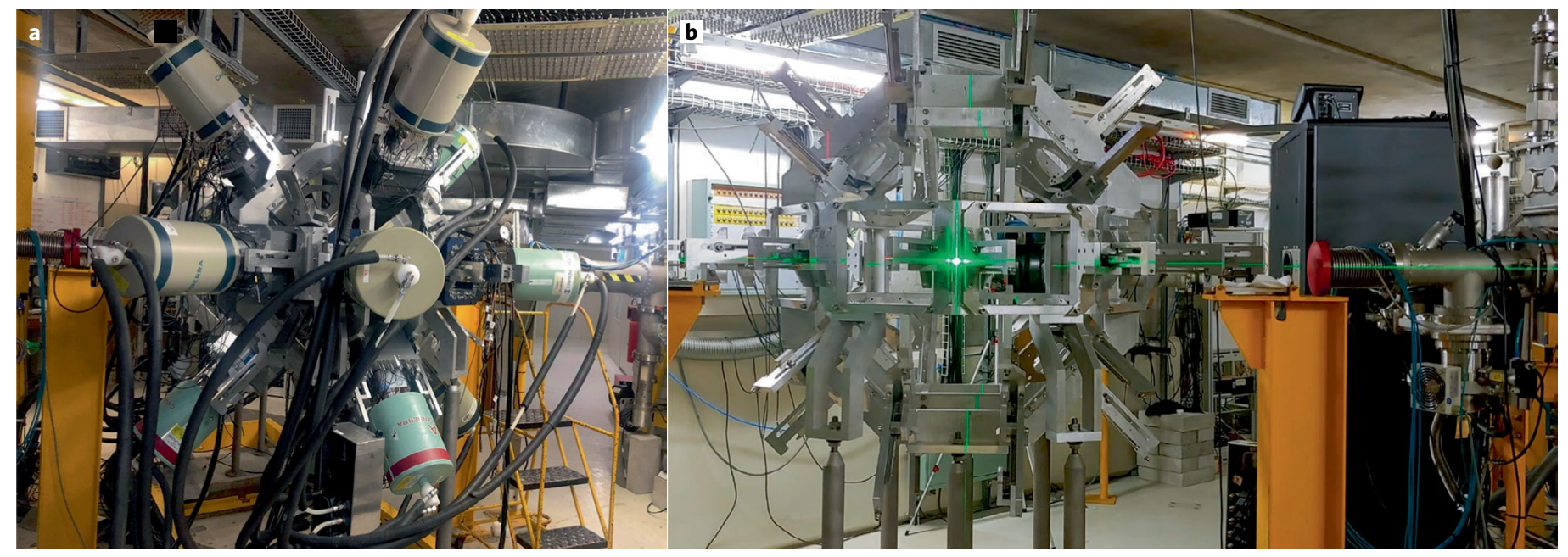

Fig. 2 | The GAMKA nuclear spectrometer. a,b, The Gamma-ray Spectrometer for Knowledge in Africa (GAMKA) uses a large array of gamma-ray detectors (a), which is aligned with the help of laser beams (b). Credit: Courtesy of J. N. Orce.

long-standing impact in the field of nuclear physics ${ }^{10-15}$.

\section{Ties for training}

Given the relative geographic isolation of South African institutions, our students are in need of international exposure to improve scientific training and boost their self-confidence. This is achieved in two ways.

First, students are given a chance to go overseas to gain hands-on experience. For example, student exchange programmes with the universities of Kentucky, Washington and York enable long-term stays dedicated to training with accelerators, gamma spectroscopy, particle detectors or simulations. In addition, experiments are set up and run at various nuclear physics facilities, such as CERN, iThemba LABS in South Africa and TRIUMF in Canada, and students get the chance to present their work at national and international conferences.

Second, students' education is enriched by visits from renowned international scientists, such as Nobel Laureate Serge Haroche (https://go.nature.com/3utoy8r). Such events are complemented with the acclaimed 'Tastes of Nuclear Physics' conference series, a linear combination of a school, workshop and conference (https://go.nature.com/3AT0kqG), which brings students together with leaders in the fields of nuclear physics and nuclear astrophysics to motivate and encourage them towards pursuing degrees in these fields. Even during the COVID-19 pandemic, the fully virtual event connected more than 600 registrants worldwide ${ }^{16}$.

A cornerstone in the efforts to encourage students to pursue a career in nuclear physics is the Honours/MSc programme in Nuclear and Material Sciences founded in

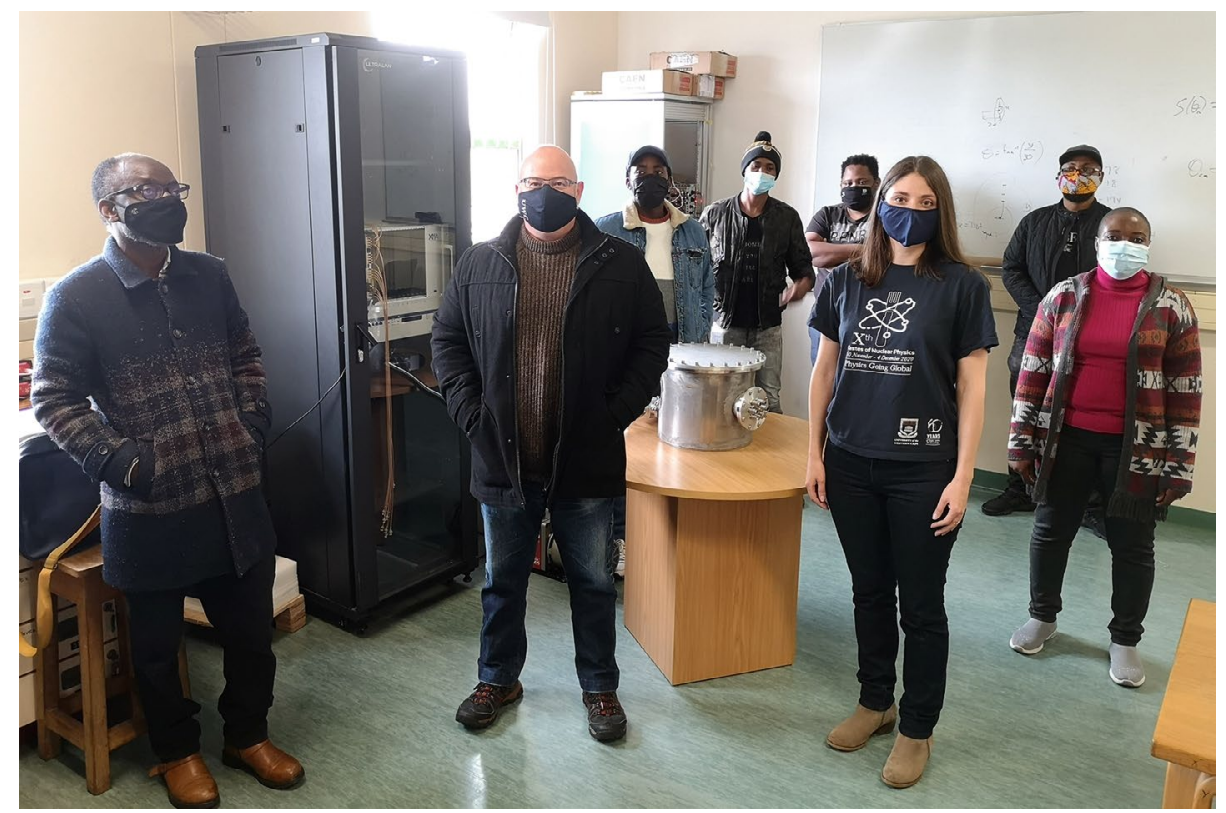

Fig. 3 | MANDELA project at the University of the Western Cape. The Modern African Nuclear Detector Laboratory (MANDELA) project aims to train students, who have access to state-of-the-art equipment required for nuclear physics experiments. Credit: Courtesy of Christopher Shear.

2004 by former director of iThemba LABS John Sharpey-Schafer as a human capital development programme for physics. The programme provides fully funded bursaries for three years, which benefits our students, who predominantly come from historically disadvantaged backgrounds and over $90 \%$ of which are Black South Africans. With over 200 graduates, the programme is arguably one of the most successful in Africa, and its human capital development is outstanding. For example, about 50 students (45 MSc and $5 \mathrm{PhDs}$ ) have graduated at UZ since
2004, feeding the world's leading diamond or network security companies, as well as academia. By contrast, only one student graduated with an MSc degree in physics before 2004 .

\section{From collaborators to leaders}

A self-sustained transformation to achieving high scientific impact also requires the development of state-of-the-art equipment and strong $\mathrm{PhD}$ programmes. In line with this effort, the GAMKA (Gamma-ray Spectrometer for Knowledge 


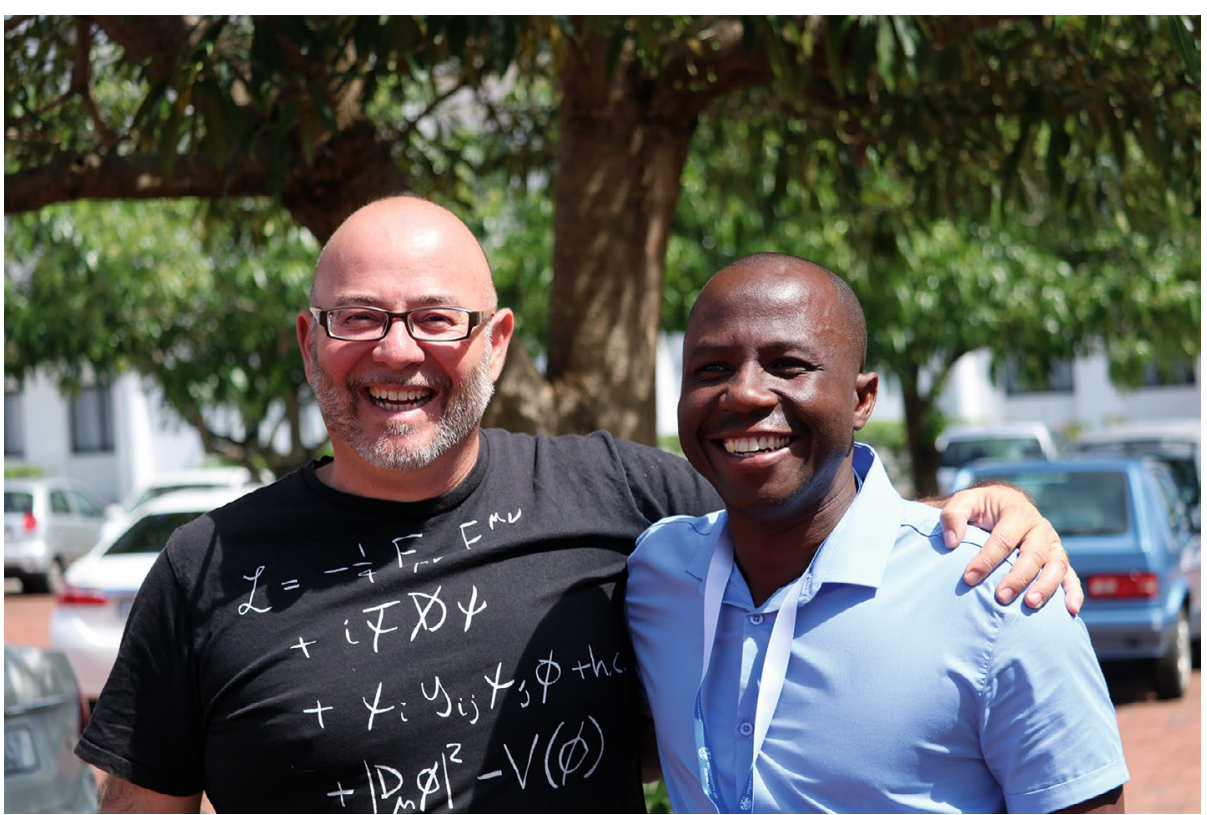

Fig. 4 | The authors at UZ. Nico Orce and Sifiso Ntshangase at UZ during the IX Tastes of Nuclear Physics in 2019 with over 50 world-class speakers and 200 attendees. Credit: Courtesy of Zipho Ngcobo.

in Africa) and MANDELA (Modern African Nuclear Detector Laboratory) projects have made South African facilities internationally competitive.

GAMKA (Fig. 2), which means 'lion' in the Khoi-San language of South Africa, is a UWC-led project comprising a consortium of South African institutions, including UZ, iThemba LABS, Stellenbosch University and the University of the Witwatersrand. GAMKA received the single largest grant - over 35 million rands (around 2 million euros) - given by the National Research Foundation of South Africa in a competitive call (https://go.nature.com/39KVHD9). And after almost a decade, it has now become a reality, with experiments set to commence in 2021, using a large array of gamma-ray detectors equipped for superior energy resolution and high efficiency. Another important aspect of the GAMKA project involves technology transfer with local companies, which has led to commissions for parts of the ISOLDE decay station at CERN.

As of this year, the GAMKA array is available to the local and international nuclear physics community for conducting experiments. Its use - as in any other accelerator facility - generally involves demanding set ups and running of high-priority experiments, which have prior approval by an international advisory committee. This tight schedule clearly limits the opportunities for training students in such facilities, but the MANDELA project ${ }^{17}$ (Fig. 3) aims to address this issue. It offers two state-of-the-art laboratories at UWC (https://go.nature.com/2Y6Jg24) and UZ, funded by these institutions and the United Kingdom's Science and Technology Facilities Council's Global Challenge Programme. The laboratories are fully equipped with both analogue and digital acquisition systems, self-designed vacuum chambers, particle and gamma-ray detectors, and fast computers. The project aims to support GAMKA with ancillary equipment, and to develop new positron emission tomography scanners ${ }^{18}$ for free cancer imaging in Africa.

Through the spirit of Ubuntu, we have contributed to real transformation in South Africa by building strong role models and providing scientific and academic leadership (Fig. 4). This is reflected in the 2016 Nature Index, which tracks the affiliations of high-quality scientific articles from the beginning of June 2015 to end of May
2016: UWC is ranked number one in the physical sciences on the African continent (see https://go.nature.com/3kOmc0z for a related interview). With our efforts to bring pride to the historically disadvantaged communities of South Africa, we hope that we have gained visibility and recognition not only from the worldwide nuclear physics community but also from the little boy at the shelter.

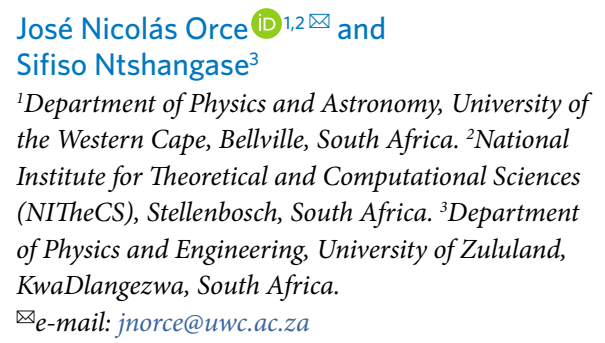
the Western Cape, Bellville, South Africa. ${ }^{2}$ National Institute for Theoretical and Computational Sciences (NITheCS), Stellenbosch, South Africa. ${ }^{3}$ Department of Physics and Engineering, University of Zululand, KwaDlangezwa, South Africa.

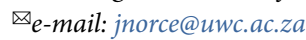

Published online: 28 October 2021 https://doi.org/10.1038/s41567-021-01397-8

\section{References}

1. Orce, J. N. J. Phys. Conf. Ser. 455, 012041 (2013).

2. Butler, P. A. et al. Phys. Rev. Lett. 124, 042503 (2020).

3. Butler, P. A. et al. Nat. Commun. 10, 2473 (2019).

4. Kumar Raju, M. et al. Phys. Lett. B 777, 250-254 (2018).

5. Ngwetsheni, C. \& Orce, J. N. Phys. Lett. B 792, 335-339 (2019).

6. Rebeiro, B. M. et al. Phys. Lett. B 809, 135702 (2020).

7. Nzobadila Ondze, J. C. et al. Phys. Rev. C 103, 034329 (2021).

8. Mukwevho, N. J. et al. Phys. Rev. C 98, 051302(R) (2018).

9. Ngwetsheni, C. \& Orce, J. N. Hyperfine Interact. 240, 94 (2019).

10. Sithole, M. A. et al. Phys. Rev. C 103, 024325 (2021).

11. Orce, J. N. Int. J. Mod. Phys. E 29, 203002 (2020).

12. Ngwetsheni, C. \& Orce, J. N. EPJ Web Conf. 223, 01045 (2019).

13. Garrett, P. E. et al. Phys. Rev. Lett. 123, 142502 (2019).

14. Lawrie, E. A., Shirinda, O. \& Petrache, C. M. Phys. Rev. C 101, 034306 (2020).

15. Mthembu, S. H. et al. Nucl. Instrum. Methods A 1008, 165458 (2021).

16. Orce, J. N. Nucl. Phys. News 31, 35-36 (2021).

17. Kapoor, K. et al. Hyperfine Interact. 240, 64 (2019).

18. Watts, D. P. et al. Nat. Commun. 12, 2646 (2021).

\section{Acknowledgements}

We acknowledge funding for the MANuS/MatSci Honours/Masters programme by the National Research Foundation of South Africa and financial assistance by the South Africa-CERN collaboration. We also thank K. Bharuth-Ram, U. Bawa, M. Orce and A. Garciolo for proofreading this manuscript and providing a historical background to the development of science in South Africa. GAMKA is supported by the National Research Foundation of South Africa (Strategic Research Equipment Grant Number: 114668), and by contributions from the consortium iThemba LABS, Stellenbosch University, University of the Western Cape, University of the Witwatersrand and the University of Zululand.

Competing interests

The authors declare no competing interests. 